\title{
Prevalence of Diabetes Mellitus and Associated Factors in Southern Ethiopia: A Community Based Study
}

\author{
Alemayehu Zekewos ${ }^{1}$, Eskindir Loha ${ }^{2}$, Tariku Egeno ${ }^{3}$, Kindie Wubshet ${ }^{3}$, \\ Zelalem Merga ${ }^{4}$
}

OPEN ACCESS
Citation: Zekewos A, Loha E, Egeno
T, Wubshet K, Merga Z. Prevalence
of Diabetes Mellitus and Associated
Factors in Bona District, Sidama Zone: A
Community Based Study. Ethiop J
Health Sci.2017; 28 (4):451.
doi:http://dx.doi.org/ 10.4314/ejhs. v28i4.11
Received: February 3, 2018
Accepted: February 6, 2018
Published: July 1, 2018
Copyright: O 2018 Zekewos
Alemayehu, et al. This is an open access
article distributed under the terms of the
Creative Commons Attribution License,
which permits unrestricted use,
distribution, and reproduction in any
medium, provided the original author and
source are credited.
Funding: Bona District Health Bureau
and Abem private clinic.
Competing Interests: The authors
declare that this manuscript was
approved by all authors in its form and
that no competing interest exists.
Affiliation and Correspondence:
${ }^{1}$ Bioghemistry Unit, College of
Medicine and Health Science,
Hawassa University, Ethiopia
${ }^{2}$ College of Medicine and Health
Science, Hawassa University, Ethiopia
${ }^{3}$ Internal Medicine, College of
Medicine and Health Science,
Hawassa University, Ethiopia
${ }^{4}$ Surgery, Bona Hospital, Bona,
Ethiopia
*Email: alemzeke@yahoo.com

ABSTRACT

BACKGROUND: Like in all populations of the world, recently, diabetes became serious health problem in Ethiopian population, as indicated by few community-and institution-based studies. As high as $6.5 \%$ diabetes prevalence was reported in Addis Ababa while $5.1 \%$ in urban setting and $2.1 \%$ in rural setting of Northwest Ethiopia have been reported. This study aimed to provide additional data on the magnitude of diabetes and associated risk factors. The study aimed to determine the prevalence of diabetes in Bona District and identify contributing risk factors.

METHODS AND MATERIALS: A cross-sectional community based survey for diabetes and associated factors was done from February-June, 2016 on a total of 2670 participants in the age range of 15-110 years. Participants were recruited to the study by using a two-stage simple random sampling technique. Data were collected by using structured questionnaire from consented participants. Data were entered, checked for quality and analyzed using SPSS for Windows version 20.0. Since the outcome variable was ordered categorical, we used ordinal regression model to identify associated factors. There was no multicollinearity among the independent variables included in the model. All the independent variables with $p<0.25$ during bivariate analysis were included in the multivariate model. The level of significance was set at $P$ value $<0.05$.

RESULTS: The overall prevalence of diabetes (1.9\%) from our survey was so high in rural setting that prevention and control mechanisms should be designed. The risk factors include advanced age $(\beta=1.04(0.57-1.50))$, systolic hypertension $(\beta=0.59(0.01-1.18))$, high waist circumference $(\beta=0.86(0.34-1.39))$ and postsecondary education $(\beta=0.87(0.03-1.71))$.

KEYWORD: Diabetes, prevalence, risk factors

\section{INTRODUCTION}

Diabetes is the commonest disease of the endocrine system, with changes in metabolism of carbohydrates, lipids and proteins. Chronic complications such as neuropathy, nephropathy, retinopathy and cardiovascular diseases are common in long-standing uncontrolled diabetes (1-3). The two major forms of diabetes are 
type 1 diabetes (accounts about 10\% diabetes cases worldwide), which results from absolute deficiency of insulin due to autoimmune destruction of pancreatic $\beta$-cells and type 2 (90\% of all diabetic cases worldwide), which results from insulin resistance and/or relatively insufficient insulin secretion $(1,4-7)$. Type 1 diabetes usually affects children or young adults while type 2 diabetes most often happens in adults, but it is increasingly affecting children and adolescents $(1,2)$. Type 2 diabetes may remain undiagnosed until complications become evident since the disease develops gradually.

Formerly, diabetes has been a disease affecting developed countries and wealthy people. However, recently, it became a health problem in all population in the world, particularly developing countries (8). In the last few decades, the prevalence of diabetes increased alarmingly reaching to epidemic level, affecting people in all age groups in both urban and rural settings $(2,5)$. Several authors have estimated and projected the prevalence of diabetes in different years and for different years, respectively $(2,5,8-12)$. However, most of them have projected less than actually detected. For example, Danaei et al have reported that in 2008 about 347 million people had diabetes worldwide (10), which is much lower than that of 258 million people projected by Shaw and his colleagues for 2010 (11).

According the International Diabetes Federation (IDF) report, the number of people having diabetes was 415 million in 2015 and projected to rise to 642 million in 2040. The same report estimated that in the age group of 20-79 years, the global prevalence of diabetes was $8.8 \%$ in 2015 and projected to be $10.4 \%$ in 2040 (13). The worst scenario is that diabetes is increasingly encroaching productive population groups (14), as reported by IDF in 2015 about $77.3 \%$ of people with diabetes are in the age range of 20-64 years (13). Many scholars believe that the shocking increase in diabetes prevalence in all populations of the world could be attributed to amenable risk factors such as habit of unhealthy diets, physical inactivity, increasing proportion of overweight and obese people, excess intake of alcohol and increasing urbanization(4,13,15-19).
The increase of diabetic prevalence is now becoming more significant in developing countries than in developed countries, where there are scarce resources for diabetic management, contributing to increased risk of premature morbidity and mortality with major social and economic consequences (2). In 2015, the estimated revalence of diabetes was $3.2 \%$, which is projected to be $3.7 \%$ in 2040 in African region (13), which comprises most developing countries including Ethiopia. However, data on diabetes prevalence is scarce in developing countries, in particular sub-Saharan Africa and rural populations $(17,20)$. The Ethiopian Diabetes Association (EDA) estimated 2-3\% prevalence in 2013 in Ethiopia. In 2015, the Ethiopian Diabetes Association (1.33 million) and IDF (1.30 million) reported almost the same number of people live with diabetes in the country (13).

Many of the studies done on diabetes so far in Ethiopia focused on the glycemic control, dyslipidemia and acute and chronic complications of diabetes among diabetic patients (21-28). Few community based and institution based studies documented data on prevalence of diabetes in Ethiopia, which can be used as preliminary information on the effect of diabetes on Ethiopian population (15,29-31). A community based study on bank workers and teachers (29) and a hospital based study (31) reported diabetes prevalence of $6.5 \%$ in Addis Ababa. Another community based study in Northwest Ethiopia indicated that the prevalence of diabetes in the population aged 35 years and above is $5.1 \%$ in urban setting and $2.1 \%$ in rural setting (15). No community based survey of diabetes was done in the study area in particular as well in Sidama Zone and South Nations, Nationalities, and People's Regional (SNNPR) State at large. Therefore, this community based survey aimed to generate information on the prevalence of diabetes in the study area and identify contributing risk factors.

\section{MATERIALS AND METHODS}

DOI: http://dx.doi.org/10.4314/ejhs.v28i4.11 
Study setting and design: This is a crosssectional community based study conducted on 2670 participants in Bona District, Sidama Zone, South Ethiopia, from February to June 2016. Bona District ('woreda' in Ethiopia setting), is one of the 19 districts in Sidama Zone, SNNPR State. According to the national census, in 2011 the population size of the district was about 135,816 , which is about $4 \%$ of the total population $(3,406,188)$ of Sidama Zone. The district has 20 villages ('kebele', the smallest administrative unit in Ethiopia).

Individuals with age of 15 years and above, living in Bona District, who lived at least half a year in the study area and those who gave informed consent were included in the study. Pregnant women, severely ill patients at the time of sample collection, and individuals with fever, infection, congestive heart failure and known endocrine disorders like Cushing's syndrome were excluded from the study.

Sampling techniques: The sample size was estimated by taking 0.50 proportion since national prevalence for diabetes is lacking. The calculated sample size at $95 \%$ confidence interval and absolute precision (d) of 0.02 was 2401. Since we had blood glucose test strips from Ethiopian Diabetes Association, we topped the sample size to 3000. A two-stage random sampling technique was applied to select study participants. From 20 villages of the district, 10 were selected by lottery method, and each village was allocated sample size proportional to the total households in each village. A constant number $\mathrm{k}$ was obtained by dividing the total household in each selected village by the sample size allotted to the respective village. Then, the first household was selected from each selected village randomly by lottery method, and subsequent households were selected by taking consecutive $\mathrm{k}^{\text {th }}$ households until the allotted sample size for each village was obtained. Only one participant was recruited into the study from a household, by using lottery method in households where there were more than one eligible individuals.

Data collection: The data were collected by data collectors composed of general practitioners and nurses who were able to speak and write the local language. The data collectors were given a one day training about the study and the data collection process by the principal investigator. To ensure data quality, the questionnaire was standardized by $5 \%$ pretesting and random supervisions were done by investigators. The general practitioners made physical examination for clinical conditions for consented individuals before they were interviewed by trained nurses using structured questionnaire in three categories: socio-demographic information, previous history of diabetes and hypertension, and family history of diabetes mellitus and hypertension. After the interview, anthropometric parameters and random blood glucose were measured for each participant.The random blood glucose was determined by using glucometer-strip method by finger puncture. According to the American Diabetes Association's guideline, random blood glucose levels $<140 \mathrm{mg} / \mathrm{dl}$ was considered as normal, $140-199 \mathrm{mg} / \mathrm{dl}$ as impaired glucose regulation and $\geq 200 \mathrm{mg} / \mathrm{dl}$ defined as diabetes (7).Whenever random blood glucose level indicates case of diabetes $(\geq 200 \mathrm{mg} / \mathrm{dl})$ and impaired glucose regulation $(140-199 \mathrm{mg} / \mathrm{dl})$, it was confirmed by measuring fasting blood glucose levels. Participants who were unaware of that they had diabetes prior to the study were linked to Bona Primary Hospital for further diagnosis and management of their conditions.

Weight was measured to the nearest 0.1 kilogram $(\mathrm{kg})$ using a person scale when the participants were in light indoor clothing and bare feet. Height was measured to the nearest 0.01 meter $(\mathrm{m})$ by a stadiometer when the participants were in erect position without shoes. Body mass index (BMI) was calculated by dividing weight in kilograms by square of height in meters. BMI $<18.0 \mathrm{~kg} / \mathrm{m}^{2}$ is taken as underweight, $18.0-24.9 \mathrm{~kg} / \mathrm{m}^{2}$ as normal weight, $25.0-29.9$ as overweight and $\geq 30 \mathrm{~kg} / \mathrm{m}^{2}$ as obese (32). Waist circumference was measured in centimeter $(\mathrm{cm})$ by placing a tape meter horizontally, midway between the $12^{\text {th }}$ rib and the iliac crest on the mid-axillary line. Male participants with waist circumference of $\geq 94 \mathrm{~cm}$ were considered as having central obesity whereas female participants with $\geq 80 \mathrm{~cm}$ waist circumference were considered as having central

DOI: http://dx.doi.org/10.4314/ejhs.v28i4.11 
obesity (32). Blood pressure was measured after at least 5 minutes of rest using an appropriate mercury sphygmomanometer and expressed in mmHg. Hypertension was defined based on WHO criteria, systolic blood pressure $\geq 140 \mathrm{mmHg}$ or diastolic blood pressure $\geq 90 \mathrm{mmHg}$ (33) or reported regular use of anti-hypertensive drug. The measurements were taken two times and the average values were recorded.

Data analysis: Data were entered, cleaned, coded and analyzed by using SPSS for Windows version 20.0 (IBM, USA). The data were cleaned by using sort cases tool and whenever missing and/or unexpected values were identified, that value was checked in the filled hardcopy data collection questionnaire to correct data entry mistakes. The data were expressed in range, mean and standard deviation of the mean, median, inter-quartile range and $p$-values if necessary. Since the outcome variable was ordered categorical, we used ordinal regression model to identify associated factors. Collinearity diagnostics was done, and there was no multicollinearity among the independent variables included in the model. All the independent variables with $p<0.25$ during bivariate analyses were included in the multivariate model. A regression coefficient $(\beta)$ with $95 \%$ CI was reported, while the level of significance was set at $\mathrm{p}<0.05$.

Ethical approval: The research protocol was approved by the South Nations, Nationalities and Peoples' Reginal State Health Bureau Ethical Review Committee. Every effort was made to keep personal information in the research record private and confidential. Written informed consent was obtained from each participant before data collection. In cases where the participants were below the age of 18 years, informed consent was obtained from their parents or guardians before data collection.

\section{RESULTS}

Characteristics of study participants: Initially, data were collected from 2922 study participants. However, during clearance of data for missing and unexpected values, 252 participants had unrepairable missing and/or unexpected value(s) and were excluded from analysis. Thus, finally, 2670 participants were included in the study. Table 1 depicts the socio-demographic and anthropometric characteristics of the study participants. Males accounted for $56.9 \%$ while females constituted $43.1 \%$ of the study participants. Most (97.3\%) of the participants were of Sidama ethnic group.

The median age of the study participants was $32(23-47)$ years, and $63 \%$ of them were below the age of 40 years while $37 \%$ were 40 years and above. Most of the study participants had elementary education (39.1\%), followed by $35.5 \%, 19.1 \%$ and $6.2 \%$ of illiterate, secondary, and postsecondary education, respectively. The average family size was 6.44 (2.76), which is similar to family size commonly observed in developing countries. When grouped into two, $36.4 \%$ of the study participants lived in families of five or less members while the rest $63.6 \%$ lived in families of more than 5 members. Though the method used to estimate family income was not appropriate in rural setting, the median family income was 417 (200-1000) Birr, and 58.5\% of the participants reported having monthly income of 500 or less Birr while the rest $41.5 \%$ reported that they had more than 500 Birr monthly family income.

The mean systolic and diastolic blood pressure, respectively, were 115.1 (19.6) $\mathrm{mmHg}$ and 74.6 (12.6) $\mathrm{mmHg}$. According to the WHO definition of hypertension (33), $77.8 \%$ of the study participants had normal systole blood pressure, $9.4 \%$ of them had systolic prehypertension and $12.8 \%$ of them had systolic hypertension. Based on diastole blood pressure data, most $(86.0 \%)$ of them were normal; a very small proportion $(0.6 \%)$ had prehypertension and $13.4 \%$ of them had hypertension. Two hundred sixteen $(8.1 \%)$ of the participants had combined hypertension. While most of the study participants $(80.4 \%)$ had normal body mass index (BMI), remarkable proportion $(13.1 \%)$ of them were underweight and only $6.5 \%$ of them were overweight and obese.

DOI: http://dx.doi.org/10.4314/ejhs.v28i4.11 
Table 1: Sociodemographic and anthropometric characteristics of study participants $(\mathrm{N}=2670)$.

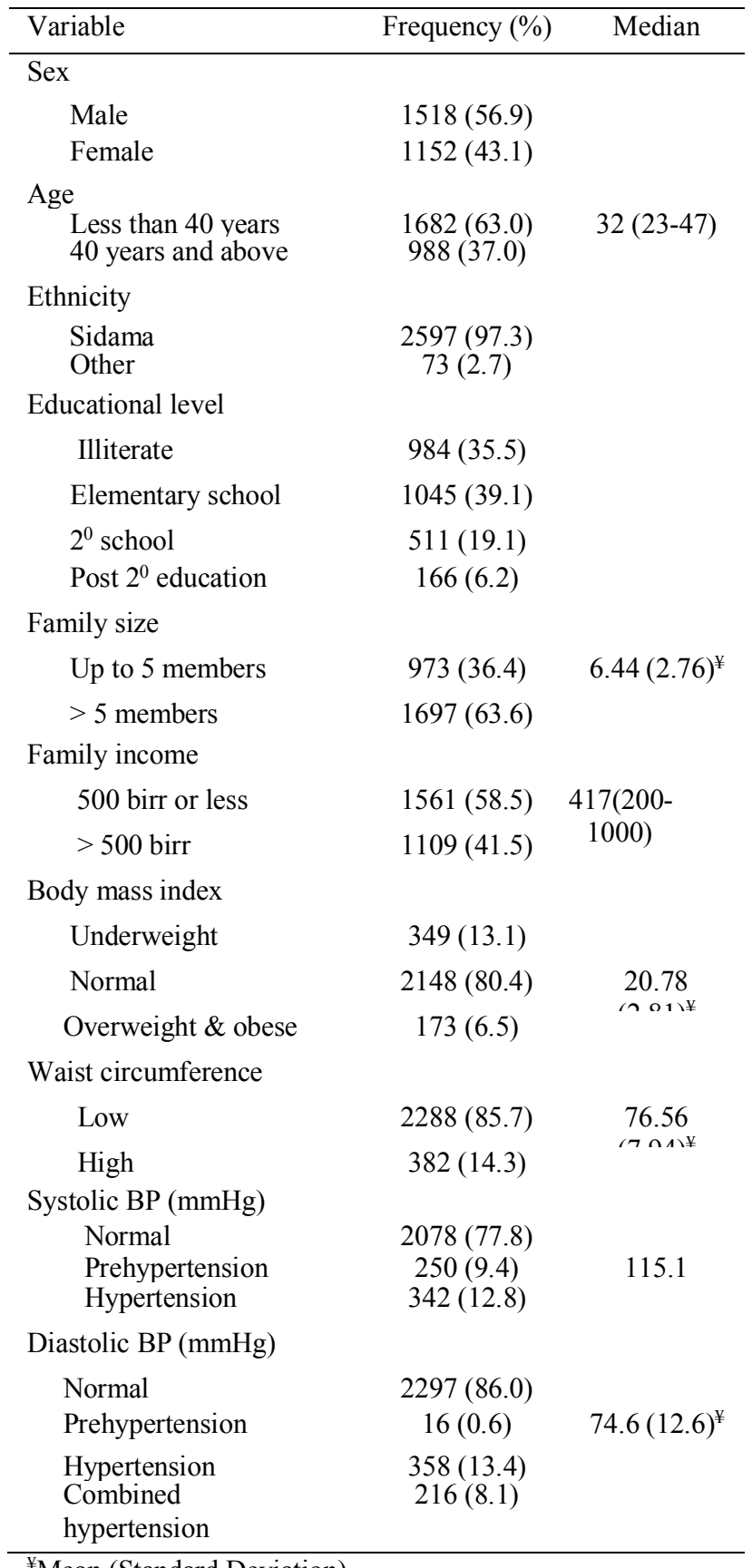

${ }^{\ddagger}$ Mean (Standard Deviation)

Prevalence of diabetes and associated factors: The mean random blood glucose level was 105.2 (35.5) $\mathrm{mg} / \mathrm{dl}$. The prevalence of diabetes was $1.9 \%$, whereas $2.6 \%$ of the participants were prediabetes. More than half of the diabetic participants $(54.0 \%)$ were unaware that they had diabetes prior to the time of this study. Furthermore, most $(95.7 \%)$ of the participants with prediabetic blood glucose levels did not know that they had impaired regulation of their blood glucose.

The prevalence of diabetes significantly increased with age advancement; diabetes prevalence in participants with age of 40 years and above $(3.1 \%)$ is significantly higher than that in participants with age less than 40 years $(1.1 \%)$ by factor of 1.04 ((0.57-1.50), $\mathrm{P}<0.001)$. When BMI is used as measure of overweight and obesity, though the prevalence of diabetes in overweight and obese participants $(5.8 \%)$ was higher than that of $1.6 \%$ prevalence in participants with normal BMI, no significant association is observed, which may be due to small sample size in overweight and obese group. More than 14\% of the study participants have central obesity (high waist circumference), and the prevalence of diabetes is significantly higher in participants with high waist circumference $(4.2 \%)$ compared to $1.5 \%$ of the participants with low waist circumference $(\beta=0.86$ (0.34-1.39), $\mathrm{P}<0.001)$.

Regarding the association between diabetes and hypertension, the prevalence of diabetes is highest in participants with systolic hypertension (4.1\%), followed by the one in participants with systolic prehypertension $(2.0 \%)$ and those with normal systolic blood pressure (1.5\%), respectively. The chance of individuals with systolic hypertension to be diabetic is significantly higher by factor of 0.59 than those with normal systolic blood pressure $(\beta=0.59$ (0.01-1.18), $\mathrm{P}<0.046)$. In the same manner, the prevalence of prediabetes is higher in participants with systolic hypertension $(4.4 \%)$ than in participants with normal systolic blood pressure. Though not significant, diabetes is positively higher in participants with diastolic prehypertension $(6.7 \%)$ compared to individuals with normal blood pressure (1.6\%). Unexpectedly, diabetes is negatively associated with diastolic hypertension $(\beta=-0.37)$; this may be due to very small study participants in diastolic prehypertension blood pressure.

The prevalence of diabetes was not significantly associated with socio-demographic factors except educational levels. Post-secondary

DOI: http://dx.doi.org/10.4314/ejhs.v28i4.11 
education significantly increases the chance of developing diabetes $\quad(\beta=0.87 \quad(0.03-1.71)$, $\mathrm{P}<0.042$ ), which could be attributed to physical inactivity related to work environment in educated participants. As shown in Table 2, the prevalence of diabetes was twofold higher in males $(2.4 \%)$ than in females $(1.2 \%)$ though not at statistically significant level. The prevalence of diabetes was higher in those who live in families of greater than 5 members $(2.3 \%)$ in comparison to those who live in families of 5 or less members $(1.6 \%)$, but the increment in diabetes with increasing family size is not significant. In the same way, though statistically not significant, the prevalence of diabetes in participants with monthly family income higher than 500 birr $(2.3 \%)$ than in participants with monthly family income of 500 birr and less $(1.6 \%)$.

Table 2: Estimation of diabetes and ordinal logistic regression analysis of factors associated with random blood glucose levels in study participants $(\mathrm{N}=2670)$.

\begin{tabular}{|c|c|c|c|c|c|}
\hline \multirow[t]{2}{*}{ Variables } & \multicolumn{3}{|c|}{ Random blood glucose (mg/dl) } & \multirow[t]{2}{*}{$\beta[95 \% \mathrm{CI}]$} & \multirow[t]{2}{*}{$P$ value } \\
\hline & $<140(\mathrm{~N}=2551)$ & $140-199(\mathrm{~N}=69)$ & $\geq 200(\mathrm{~N}=50)$ & & \\
\hline \multicolumn{6}{|l|}{ Sex } \\
\hline Male & $1453(95.7 \%)$ & $29(1.9 \%)$ & $36(2.4 \%)$ & 1.00 & \\
\hline Female & $1098(95.3 \%)$ & $40(3.5 \%)$ & $14(1.2 \%)$ & $-0.08(-0.57-0.40)$ & \\
\hline \multicolumn{6}{|l|}{ Age } \\
\hline$<40$ years & $1636(97.3 \%)$ & $27(1.6 \%)$ & $19(1.1 \%)$ & 1.00 & \\
\hline$\geq 40$ years & $915(92.6 \%)$ & $42(4.3 \%)$ & $31(3.1 \%)$ & $1.04(0.57-1.50)$ & $<0.001$ \\
\hline \multicolumn{6}{|l|}{ BMI } \\
\hline$<18.0 \mathrm{~kg} / \mathrm{m}^{2}$ & $335(96.0 \%)$ & $9(2.6 \%)$ & $5(1.4 \%)$ & 1.00 & \\
\hline $18.0-24.9 \mathrm{~kg} / \mathrm{m}^{2}$ & $2060(95.9 \%)$ & $53(2.5 \%)$ & $35(1.6 \%)$ & $-0.04(-0.63-0.55)$ & \\
\hline$\geq 25 \mathrm{~kg} / \mathrm{m}^{2}$ & $156(90.2 \%)$ & $7(4.0 \%)$ & $10(5.8 \%)$ & $0.23(-0.61-1.08)$ & \\
\hline \multicolumn{6}{|l|}{$\mathrm{WC}$} \\
\hline Low & $2205(96.4 \%)$ & $49(2.1 \%)$ & $34(1.5 \%)$ & 1.00 & \\
\hline High & $346(90.6 \%)$ & $20(5.2 .0 \%)$ & $16(4.2 \%)$ & $0.86(0.34-1.39)$ & $<0.001$ \\
\hline \multicolumn{6}{|l|}{ Systolic BP } \\
\hline$\leq 120 \mathrm{mmHg}$ & $1998(96.2 \%)$ & $49(2.4 \%)$ & $31(1.5 \%)$ & 1.00 & \\
\hline $120-139 \mathrm{mmHg}$ & $240(96.0 \%)$ & $5(2.0 \%)$ & $5(2.0 \%)$ & $-0.14(-0.85-0.56)$ & \\
\hline$\geq 140 \mathrm{mmHg}$ & $313(91.5 \%)$ & $15(4.4 \%)$ & $14(4.1 \%)$ & $0.59(0.01-1.18)$ & $<0.046$ \\
\hline \multicolumn{6}{|l|}{ Diastolic BP } \\
\hline$\leq 80 \mathrm{mmHg}$ & $2200(95.8 \%)$ & $61(2.7 \%)$ & $36(1.6 \%)$ & 1.00 & \\
\hline $80-89 \mathrm{mmHg}$ & $14(93.3 \%)$ & $0(0.0 \%)$ & $1(6.7 \%)$ & $0.12(-1.95-2.19)$ & \\
\hline$\geq 90 \mathrm{mmHg}$ & $337(94.1 \%)$ & $8(2.2 \%)$ & $13(3.6 \%)$ & $-0.37(-0.99-0.26)$ & \\
\hline \multicolumn{6}{|l|}{ Educational level } \\
\hline Illiterate & $898(94.7 \%)$ & $37(3.9 \%)$ & $13(1.4 \%)$ & 1.00 & \\
\hline Primary school & $1001(95.8 \%)$ & $20(1.9 \%)$ & $24(2.3 \%)$ & $0.28(-0.22-0.79)$ & \\
\hline Secondary school & $496(97.1 \%)$ & $9(1.8 \%)$ & $6(1.2 \%)$ & $0.16(-0.56-0.88)$ & \\
\hline Post-secondary edu. & $156(94.0 \%)$ & $3(1.8 \%)$ & $7(4.2 \%)$ & $0.87(0.03-1.71)$ & $<0.042$ \\
\hline \multicolumn{6}{|l|}{ Family size } \\
\hline$\leq 5$ members & $939(96.5 \%)$ & $19(2.0 \%)$ & $15(1.5 \%)$ & 1.00 & \\
\hline$>5$ members & $5.0 \%)$ & $50(2$ & $35(2$ & $(-0.21-0.64)$ & \\
\hline \multicolumn{6}{|l|}{ Family income } \\
\hline$\leq 500$ birr & $1495(95.5 \%)$ & $41(2.6 \%)$ & $25(1.6 \%)$ & 1.00 & \\
\hline$>500$ birr & $1056(95.2 \%)$ & $28(2.5 \%)$ & $25(2.3 \%)$ & $0.12(-0.26-0.51)$ & \\
\hline
\end{tabular}

WC - waist circumference, BP - blood pressure, BMI - body mass index, $\beta$-regression coefficient

DOI: http://dx.doi.org/10.4314/ejhs.v28i4.11 


\section{DISCUSSION}

In this community based study, we estimated the magnitude of diabetes in rural setting. There was a great variability of age, ranging 15-110 years among the study participant, which will probably lead to wide variability of blood glucose level and thus prevalence of diabetes. The risk factors were age advancement, central obesity, systolic hypertension and postsecondary education.

The prevalence of diabetes in this study was $1.9 \%$, which is expected in rural setting and comparable to $2.1 \%$ prevalence previously reported by Abebe et al in rural Northwest Ethiopia (15) and 2.2\% prevalence of type 2 diabetes in rural Kenya based on fasting blood glucose levels (16). Furthermore, our result is the same as the estimated prevalence of diabetes in Ethiopian adult population (34). On the contrary, the prevalence of diabetes from this study is higher than that reported by Ambachew et at $(1.3 \%)$ in Northern Ethiopia (30), 1.2\% in Bank employees in Addis Ababa (35). In the same way our result is much higher than prevalence of type 2 diabetes in other Sub-Saharan countries like 0.6\% in rural Uganda, a study based on random plasma glucose test (17) and $0.8 \%$ in rural Cameroon, a study based on fasting blood glucose test/oral glucose tolerance test (36). However, our result is much lower compared to prevalence of type 2 diabetes in rural setting reported from African countries, such as $5.3 \%$ in Guinea (18), 5\% in Kenya (19), 8.8\% and 3.9\% in South Africa (37, 38). The discrepancies among results from different studies in different vicinities may be due to the socio-demographic and life style of the studied population. Our study used random blood glucose level, which may be less powerful to identify diabetes cases that the obtained prevalence may be less than the actual burden of the disease. The other limitation in comparing our results to previously reported diabetes prevalence in Sub-Saharan countries would be that we did not differentiate between type 1 and type 2 diabetes. However, still in overall, our result indicated that diabetes poses a significant health problem in rural Ethiopian population, which accounts for about $80 \%$ of the total population of the country.
More than half (54\%) of the diabetes cases were newly diagnosed in our study. This is about twofold of newly diagnosed diabetes reported by previous study (29). However, it is lower than undiagnosed diabetes in Northwest Ethiopia 69\% in urban and rural combined and $82.6 \%$ in rural setting (15). The high rate of undiagnosed diabetes may be due low cognizance of the people about the disease. It is of critical importance to increase population awareness about chronic diseases like diabetes to enhance early diagnosis of the disease and management before its progression to life threatening complication.

As expected, diabetes is associated with increasing age, significantly higher in study participants with age $\geq 40$ years. This is in agreement to previous studies in Ethiopia $(15,39)$ and elsewhere in other African countries $(18,36)$. Therefore, it is advisable to design mechanism for health education and promotion to enhance checkup for the disease as age advances. The other risk factor for development of diabetes is central obesity; high waist girth is positively and significantly associated with diabetes. Furthermore, the proportion of individuals with high waist circumference $(14.3 \%)$ is remarkable in rural setting and may contribute to alarmingly increasing prevalence of diabetes, currently, in developing countries. Previous studies from subSaharan Africa indicated that high waist circumference is a risk factor for diabetes $(16,18)$. Thus, our finding strengthens the idea that excess waist circumference plays a role in the development of type 2 diabetes. Though not significant, participants with $B M I \geq 25.0 \mathrm{~kg} / \mathrm{m}^{2}$ category have high chance of developing diabetes. The insignificant association may be due to small sample size in the BMI $\geq 25.0 \mathrm{~kg} / \mathrm{m}^{2}$ category.

Observations indicate that the link between diabetes and hypertension is bidirectional. In our study, diabetes is positively and significantly associated with systolic hypertension. Our finding is in agreement with a previous study in Guinea (18). Previous studies in different regions of Ethiopia indicated that the prevalence of hypertension is high and increasing $(29,40)$, as also observed in this study. Crude systolic hypertension, diastolic hypertension, and combined hypertension of $12.8 \%, 13.4 \%$, and

DOI: http://dx.doi.org/10.4314/ejhs.v28i4.11 
$8.1 \%$, were observed in this study.Thus, we speculate that the increasing prevalence of hypertension may play its role in increasing prevalence of diabetes.

The prevalence of diabetes $(1.9 \%)$ obtained in this survey is remarkably high in rural setting where the disease is encroaching Ethiopians. As indicated in previous studies in the country and elsewhere, our result supports the idea that controllable risk factors, like central obesity, hypertension and physical inactivity may play roles in increasing prevalence of diabetes in both developed and developing countries. The high percentage of participants who did now know their condition indicates the low awareness of the population about this life scrambling disease. Therefore, nationwide survey is needed to get the clear figure and enforce prevention, early detection and management strategies.

\section{ACKNOWLEDGMENT}

The authors gratefully thank the Ethiopian Diabetes Association for providing glucometer strips. Our heartily thank is extended to Bona District Health Bureau and Abem private clinic at Hawassa, Ethiopia, for offering the rest of the study budget.

\section{REFERENCES}

1. Girach A MD, and Porta M. Diabetic microvascular complications: can patients at risk be identified? A review. Blackwell Publishing Ltd Int. $J$ Clin Pract, 2006;60(11):1471-83.

2. IDF. IDF Diabetes Atlas. Brussels: International Diabetes Federation, Belgium. $2013 ; 6^{\text {th }}$ ed.

3. Yamagishi $\mathrm{S}$ and Imaizumi $\mathrm{T}$. Diabetic vascular complications: pathophysiology, biochemical basis and potential therapeutic strategy. Curr Pharm Des, 2005;11:2279-99.

4. Shaw J, Schneider H, and Zimmet $P$. Guidelines for the Detection of Diabetes Mellitus -Diagnostic Criteria and Rationale for Screening. Clin Biochem Rev, 2003;24:77-80.
5. IDF. IDF Diabetes Atlas. Brussels: International Diabetes Federation, Belgium. $2011 ; 5^{\text {th }}$ ed.

6. WHO. Definitions, Diagnosis, and Classification of Diabetes Mellitus and its Complications - Part 1: Diagnosis and Classification of Diabetes Mellitus. WHO, 1999.

7. ADA. Diagnosis and Classification of Diabetes Mellitus. Diabetes Care, 2008;31(Supplement 1):S55-S60.

8. Wild S, Roglic G, Green A, Sicree R, and King H. Global prevalence of diabetes: estimates for the year 2000 and projections for 2030. Diabetes Care, 2004;27(5):1047-53.

9. IDF. IDF Diabetes Atlas. Brussels: International Diabetes Federation, Belgium. $2003 ; 2^{\text {nd }} \mathrm{ed}$.

10. Danaei G, Finucane M, Lu Y, Singh GM, Cowan MJ, Paciorek CJ, Lin JK, Farzadfar F, Khang YH, Stevens GA, Rao M, Ali MK, Riley LM, Robinson CA, and Ezzati M. National, regional, and global trends in fasting plasma glucose and diabetes prevalence since 1980: systematic analysis of health examination surveys and epidemiological studies with 370 country-years and 2.7 million participants. Lancet, 2011;378(9785):31-40.

11. Shaw JE, Sicree R, and Zimmet PZ. Global estimates of the prevalence of diabetes for 2010 and 2030. Diabetes Res Clin Pract, 2009;87:4-14.

12. King H, Aubert RE and Hermen WH. Global burden of diabetes, 1995-2025: prevalence, numerical estimates, and projections. Diabetes Care, 1998;21:1414-31.

13. IDF. IDF Diabetes Atlas. Brussels: International Diabetes Federation, Belgium. $2015 ; 7^{\text {th }}$ ed.

14. Zimmet $P$, Magliano D, Herman W, and Shaw J. Diabetes: a 21 st century challenge. Lancet Diabetes Endocrinol, 2014;2:56-64.

15. Abebe SM, Berhane Y, Worku A and Assefa A. Diabetes mellitus in North West Ethiopia: a community based study. BMC Public Health, 2014;14(97):1-8.

16. Christensen DL, Friis H, Mwaniki DL, Kilonzo B, Tetens I, Boit MK, Omondi B,

DOI: http://dx.doi.org/10.4314/ejhs.v28i4.11 
Kaduka L, and Borch-Johnsen K. Prevalence of glucose intolerance and associated risk factors in rural and urban populations of different ethnic groups in Kenya. Diabetes Res Clin Pract, 2009;84(3):303-10.

17. Maher D, Waswa L, Baisley K, Karabarinde A, Unwin N and Grosskurth H. Distribution of hyperglycaemia and related cardiovascular disease risk factors in low-income countries: a cross-sectional population-based survey in rural Uganda. International Journal of Epidemiology, 2010;40(1):160-71.

18. Balde NM, Diallo I, Balde MD, Barry IS, Kaba L, Diallo MM, Kake A, Camara A, Bah D, Barry MM, Sangare-Bah M, and Maugendre D. Diabetes and impaired fasting glucose in rural and urban populations in Futa Jallon (Guinea): prevalence and associated risk factors. Diabetes Metab, 2007;33(2):11420.

19. Mathenge W, Foster A, and Kuper H. Urbanization, ethnicity and cardiovascular risk in a population in transition in Nakuru, Kenya: a population-based survey. BMC Public Health, 2010;10: 569.

20. Hall V, Thomsen RW, Henriksen O and Lohse N. Diabetes in Sub Saharan Africa 1999-2011: Epidemiology and public health implications a systematic review. BMC Public Health, 2011;11(564):1-12.

21. Seyoum B, Abdulkadir J, Berhanu P, Feleke Y, Mengistu Z, Worku Y, and Ayana G. Analysis of serum lipids and lipoproteins in Ethiopian diabetic patients. Ethiopian Medical Journal, 2003;41(1):1-8.

22. Gill G, Gebrekidan A, English P, Wile D, and Tesfaye A. Diabetic complications and glycaemic control in remote North Africa. QJM, 2008;101(10):793-8.

23. Gudina EK, Amade S, Tesfamichael FA, and Ram R. Assessment of quality of care given to diabetic patients at Jimma University Specialized Hospital diabetes follow-up clinic, Jimma, Ethiopia. BMC Endocr Disord, 2011;11(19):1-9.

24. Feleke $Y$ and Enquselassie F. An assessment of the health care system for diabetes in Addis Ababa, Ethiopia. Ethiop $J$ Health Dev, 2005;19(3):203-10.
25. Ejigu A. Patterns of chronic complications of diabetic patients in Menelik II hospital, Ethiopia. Ethiop $J$ Health Dev, 2000;14(1):113-6.

26. Lester FT. Long-standing diabetes mellitus in Ethiopia: A survey of 105 patients. DIABETOLOGIA. 1983;25 (3):222-5.

27. Worku D, Hamza L, and Woldemichael K. Patterns of Diabetic Complications at Jimma University Specialized Hospital, Southwest Ethiopia. Ethiop J Health Sci, 2010;20(1):339.

28. Seyum B, Mengistu Z, Berhanu P, Abdulkadir J, Feleke Y, Worku Y and Ayana G. Retinopathy in Tikur Anbessa hospital diabetic clinic. Ethiop Med J, 2001;39(2):12331.

29. Nshisso LD, Reesea A, Gelaye B, Lemma S, Berhane Y, and Williams MA. Prevalence of Hypertension and Diabetes among Ethiopian Adults. Diabetes Metab Syndr, 2012;6(1):3641.

30. Ambachew Y, Kahsay S, Tesfay R, Tesfahun $\mathrm{L}$, Amare $\mathrm{H}, \mathrm{G} / \mathrm{her} \mathrm{G}$ and Mehari A. Prevalence of diabetes mellitus among patients visiting medical outpatient department of Ayder referral hospital, Mekelle, Ethiopia: A three years pooled data. International Journal of Pharma Sciences and Research (IJPSR), 2015;6(2):435-9.

31. Gizaw M, Harries AD, Ade S, Tayler-Smith K, Ali E, Firdu N, and Yifter H. Diabetes mellitus in Addis Ababa, Ethiopia: admissions, complications and outcomes in a large referral hospital. Public Health Action, 2015;5(1):74-8.

32. Lau DC, Douketis JD, Morrison KM, Hramiak IM, Sharma AM, and Ur E. 2006 Canadian clinical practice guidelines on the management and prevention of obesity in adults and children [summary]. CMAJ, 2007;176(8):S1-S13.

33. Mathers C, Stevens G, and Mascarenhas M. Global health risks: mortality and burden of disease attributable to selected major risks. Geneva, Switzerland: World Health Organization, 2009.

34. Solomon AF, Chalachw M, Hawult T. Assessment of the level and associated factors

DOI: http://dx.doi.org/10.4314/ejhs.v28i4.11 
with knowledge and practice of Diabetes Mellitus among Diabetic Patients attending at Felege Hiwot Hospital, Northwest Ethiopia. Clinical Medicine Research, 2013;2(6):11020.

35. Teklu B. Chronic disease prevalence in Ethiopian bank employees. Ethiopian Medical Journal, 1982;20(2):49-54.

36. Mbanya JC, Cruickshank JK, Forrester T, Balkau B, Ngogang JY, Riste L, Forhan A, Anderson NM, Bennett F, and Wilks R. Standardized comparison of glucose intolerance in west African-origin populations of rural and urban Cameroon, Jamaica, and Caribbean migrants to Britain. Diabetes Care, 1999;22(3):434-40.

37. Alberts M, Urdal P, Steyn K, Stensvold I, Tverdal A, Nel JH and Steyn NP. Prevalence of cardiovascular diseases and associated risk factors in a rural black population of South Africa. Eur $J$ Cardiovasc Prev Rehabil, 2005;12(4):347-54.

38. Motala AA, Esterhuizen T, Gouws E, Pirie FJ and Omar MA. Diabetes and other disorders of glycemia in a rural South African community: prevalence and associated risk factors. Diabetes Care, 2008;31(9):1783-8.

39. Nigatu T. Epidemiology, complications and management of diabetes in Ethiopia: a systematic review. J Diabetes, 2012;4:174-80.

40. Abdissa SG, Feleke Yand Awol M. Prevalence of hypertension and prehypertension in Addis Ababa, Ethiopia: A survey done in recognition of World Hypertension Day, 2014. Ethiop J Health Dev, 2015;29(1):22-30. 